\title{
Effect of Assertive Training Program on Social Interaction Anxiety and Self - Esteem of Institutionalized Patients with Chronic Schizophrenia
}

\author{
Sayeda Mohamed Mohamed, D.N.Sc and Enas Mahrous AbdElAziz, D.N.Sc. \\ Psychiatric Mental Health Nursing Department, Faculty of Nursing, Cairo University
}

\begin{abstract}
This study examined the effectiveness of assertive training program on social interaction anxiety and self esteem among institutionalized patients with chronic schizophrenia. Quasi-experimental design (pre -post test-groups) was utilized in this study. The present study was conducted at the Al Abassia mental health hospital. Stratified random sample consisted of 15 institutionalized female chronic schizophrenic patients which were selected from 6 inpatient wards of chronic patients. Three tools were used to collect the data for the current study, Personal and medical data sheet, social interaction anxiety scale and the Rosenberg self-esteem scale. A constructed Assertive Training program was designed to help patients to develop and promote necessary skills for initiation and maintaining social interactions with others and to empower patients to be more assertive. This program was implemented over 15 sessions, two sessions per week and each session lasted about 60-90 minutes. Pre, post and follow up (after one month) assessment were carried out for the same group (self- control group). The current study results revealed overall significant effects of assertive training program regarding decreasing patients' social interaction anxiety while self esteem didn't show any significant result. There was a statistically significant difference between pre, post and follow up assessments, duration of institutionalization was negatively correlated with patients' self-esteem and their initiation anxiety of interaction. So, the study concluded that, the assertive training program was effective with institutionalized schizophrenic patients' concerning reducing social interaction anxiety and hence enhancing self-esteem. The study recommended that, the assertiveness training intervention should be incorporated into treatment regimen of institutionalized schizophrenic patients. In - service training programs for nurses and within undergraduate and postgraduate nursing curriculum.
\end{abstract}

Keywords: institutionalization, chronic schizophrenia, Assertive training, social anxiety, self esteem

\section{Introduction}

Schizophrenia is considering one of the top ten common conditions worldwide among young adults, as any chronic devastating illness, is characterized by a high rate of admission, relapse, chronicity and poor prognosis which impose negative impacts on patients 'functioning and cognitive abilities. So, Patients with schizophrenia struggle with considerable functional impairment, including performance of independent living skills, social functioning, and occupational/educational performance (Abo El Ella, et al 2015).

Chronicity of illness is manifested by label symptoms known as negative symptoms which contribute more toward poor functional outcome and quality of life for patients with schizophrenia than positive symptoms. Those negative symptoms as decreased spontaneous movements, poor eye contact, and loss of interest, lack of volition, easily fatigability and social withdrawal (Gogtay et al. 2011\& Husseina, et al., 2011).

Chronicity of major psychiatric disorder as schizophrenia results in social maladjustment and shows dysfunctional social skills even in remission. So, patients have experienced numerous limitations in everyday functioning, some of which include difficulties with interpersonal situations, (e.g., misinterpreting social cues, inappropriate responses to situations), problems coping with stress (including minor hassles, such as finding an item in a store), difficulty concentrating, and lack of energy or initiative. Those difficulties with inadequate rehabilitation programs lead to handicaps to social performance and even loss of learned social skills (Ho, et al., 2014\&Videbeck \& Miller, 2011).

Many studies have suggested that, institutionalization affects social functioning and quality of life significantly; because either the patients have never learnt them or they have lost them in the course of a severe mental illness (SMI). The deficits in core social skills (i.e. conversational, interpersonal relationship and assertiveness) present in various forms, such as: lack of spontaneity or clarity in conversation and inappropriate style of social interaction and relationship with others. Moreover individuals with a marked deficit in social skills find it difficult to establish and maintain social relationships and fulfill ascribed social roles. They may also find it is difficult to meet their needs, to adjust and live a stable sociallife in the community (Yadav, 2015). 
Institutionalized Schizophrenic patients show unstable levels of self-esteem and are more likely to exhibit poorer responses to treatment and have a poorer quality of life than those none institutionalized (Pedersen, 2012 \&Vieru, 2012). Although, antipsychotic medications the standard treatment for schizophrenia, are generally quite effective in reducing the positive symptoms of schizophrenia, they have only a modest effect on the negative symptoms of schizophrenia (Ebrahimi, Navidian, \&Keykha, 2014).

Patients with Low-self-esteem suffer from feelings of being weak, helpless, hopeless, frightened, fragile, in-complete, worthless and inadequate. They suffer from negative thoughts and fail to recognize their potentials, they fear criticism and take compliments negatively and are afraid of taking up responsibilities, and afraid of constituting their own opinion. Assertiveness training is the best way to deal with those situations, both in and out of work, where you feel you lack confidence. It is a way of un-hooking yourself from the learned behaviors of the past and re-programming yourself to be more assertive (Allas, 2014).

Comprehensive treatment of patients with schizophrenia focused on alleviating psychotic symptoms, improving psychosocial function, and decreasing the rate of hospitalization. For continuity of care and a favorable prognosis, early comprehensive, multidisciplinary, and programs are required for patients (Kumar, 2015 \& ElGamal, Eltybani, \&Bassim, 2012). Those programs include psycho educational programs that providing assertive training to allow the patients to feel assertive about their opinions, improve selfunderstanding, improve social interaction abilities, express their feelings without aggression and building confidence (Yadav, 2015; Mahmoud \&Abd Hamid, 2013 ; Degleris, et a., 12008 \& lin ,et al., 2008).

\section{Significance of the study}

Disturbances of social interaction in people suffering from major psychiatric illnesses have attracted concerns from clinicians, researchers, and healthcare administrators, as these deficits are a major determinant of outcome for patients. Impaired social abilities in schizophrenia are thought to be partly attributable to specific aspects of symptomatology, such as negative symptoms (blunt affect, social withdrawal, anhedonia) and disturbances of several domains of cognitive function, e.g. verbal memory, working memory, attention/vigilance, and information processing.

Schizophrenic patients have particular difficulty with the social abilities concerning interpersonal relations, assertiveness, expression of thoughts and feelings to fulfill their life role in the community. Social skill training serves to extend and create more flexibility in the individual's communication style so that he or she has a greater choice of responses in various situations. Although a change does not come easy, social skill training can be an effective way of changing behavior. Psychiatric nurses are the front-line providers of care; they are the group called on most often to carry out selective reinforcement, modeling, extinction, skills training, shaping, and role playing. Because of their direct patient contact, nurses are able to better observe patients, assess problem areas, and recommend targets for assertive training program.

Nurses also may serve as planners and coordinators of complex treatment program. Teaching assertive communication skills is an important nursing intervention, nurses assist clients to learn and practice assertive communication skills, as well as using assertive communication to communicate with other nurses and members of the health care team. Nurses can assist patients to become more assertive, thereby encouraging them to become what they want to be, promoting their self-esteem and fostering a respect for their own rights and the rights of others. So, social skill training is designed to enable schizophrenic patients to compensate for or eliminate the environmental and interpersonal barriers as well as the functional deficits created by this illness.

There are a limited number of studies which highlighted the effectiveness of group assertiveness training on social anxiety and self esteem among patients with chronic schizophrenia. Although many social problems benefit millions of chronic schizophrenic patients, no Egyptian research has been conducted. So, the investigator will conduct this study to make contribution to nursing body of knowledge because nursing care for chronic schizophrenic patients is essential in caring for those patients. The results of this study will be beneficial to mental health nurses to make program to help the chronic schizophrenic patients focusing on facilitating selfesteem and social skills among in patients with chronic schizophrenia is needed.

Also it is necessary that, social anxiety and self esteem take an active part in promoting a positive and satisfied social and psychological condition. After reviewing the pertinent literature and researches in this area, it was found that, there is a scanty research have been done in this area so the aim of the current study is to investigate the effects of group assertiveness training on social anxiety and self esteem among patients with chronic schizophrenia.

\section{Aim Of The Study:}

This study is aimed to investigate the effectiveness of assertive training program on social anxiety and self esteem of patients with chronic schizophrenia. 
Effect Of Assertive Training Program On Social Interaction Anxiety And Self - Esteem Of...

\section{Subjects And Methods Research Design}

Experimental design (pre, post and follow up test design) was used in this study

\section{Sample and sampling:}

Stratified random sample consisted of Fifteen female institutionalized chronic schizophrenics, as confirmed by senior psychiatrist at the hospital, were recruited from 6 wards for chronic patients at El-Abassia hospital for mental health in Cairo, Egypt.

Eligible patients from all chronic wards at the hospital who meet the criteria were 54 patients, (6) patients involved in pilot (7) patients refused to participate, and others were listed alphabetically, then researchers blindly selected the first member from the list, the third name after that are involved in the program till reached 20 patient whose involved on pretest assessment.

Actual patients who completed posttest were 15 patients as one patient died, 3 patients refused to continue after second sessions and other one transferred to medical hospital for surgery. After three months of ending program follow up assessment was done. Informed Consent for all participants was taken prior the beginning of the program. Patients maintained on their regular psychotropic medications, in combination with the assertiveness training program.

All participants (15) were assessed at base line (T1), then at the end of the program 3 months later (T2), and follow up assessment 2 months later (T3).

\section{Inclusion criteria for Patients selection were:}

(1)Female patients, their age ranged from 30-60 years (2) schizophrenic patients with different types who diagnosed based on (ICD -10) (3) had a duration of illness more than 3 years (4) institutionalized in the hospital for more than three years (5) Had not any evidence of organic disorder and/or alcohol or drug abuse, and (6) Able to respond in a coherent and relevant manner.

\section{Settings}

This study was conducted at AL-Abassia Psychiatric Mental Health Hospital inpatient female ward.

Tools of data collection:

Data will be collected through utilizing the following tools:

1- Personal and medical data sheet: It was developed by the researchers to elicit information about patient's age, duration of illness and duration of institutionalization.

2- Pre/post assessment tools

a- Social Interaction Anxiety Scale (SIAS), this scale was developed by Mattick and Clarke (1998). It includes 20 items that measure anxiety experienced by people in social interaction situations. All items were answered using a 5- point Likert scale format ranging from 0 (not at all) to 4 (extremely anxious), with a total score ranging from 0 to 80 . Some items are negatively stated and are scored in the opposite direction. Higher scores indicate high degree of social anxiety. The SIAS had been used in several studies and proved to be valid and reliable measure of social anxiety (Birchwood et al., 2006; Safren et al., 1998). A total score of 34 or more indicative of social phobia and 43 or more indicative of social anxiety .The SIAS, was translated into Arabic language, reviewed for the accuracy of translation and tested for content validity by three professors in psychiatric nursing, at Cairo University. The Arabic version of SIAS proved to be valid. It was also reliable using a test - retest method $(r=0.83)$.

b- The Rosenberg Self-Esteem Scale (RSES) which was originally developed by Rosenberg, (1965). Arabic version of Rosenberg self-esteem scale was used to assess self-esteem of the patient. It is a 10- item self report measure of self-esteem based upon satisfaction of one's self and life. The scale consists of five positive items and five negative items and need to be scored accordingly by reversing the value of either the positive or negative item responses. Typically, each item is answered on a four point Likert scale ranging from "strongly disagree"(1) to "strongly agree (4).According to these responses, the scale ranges from 1-40. Scores between 15 and 25 are within normal range; scores below 15 suggest low self-esteem. $0:<15$ low self esteem.

\section{Assertiveness Training Program Description:}

Assertiveness Training Program is a form of behavior therapy designed to help patients stand up and empower for themselves. The main goals were aimed to teach patients the needed skills for defending their rights, needs and opinions while remaining respectful for others and to help patients to initiate and maintain communication with others. 


\section{Specific objectives:}

a- develop skills that are necessary for initiate and maintain communication with others,

b- empower patients to be more estimated for themselves

The study program was designed to be 15 sessions implemented on four phases, where first two sessions were for assessment, program sessions were 12 sessions and final session for evaluation.

Program phases:

\section{1- Preparatory phase}

\section{a- Preparation of the content:}

The content of the program based on others related literature (Mousa, Imam, Sharaf, 2011; Kern, Glynn, Horan, \& Marder, 2009. Bögels, \&Voncken, 2008). The planning phase includes the program strategy (time table, teaching methods, and participants assignments based on each skill were given).

The content of the program includes an introduction of signs and symptoms of chronic schizophrenia, determines the influences of negative symptoms of schizophrenia on patients communication and interaction with others, identifies different patient behaviors as assertive, aggressive, and passive, The influence of each behavior (Aggressive, passive and assertive) on patients themselves and on style of communication with other patients, applies and practices assertive behavior in different situations, potentiates social interaction skills through understanding both verbal and nonverbal cues of communication with others, expressing opinion clearly, identifies patient rights and others rights, accepting criticism, being aware of how, why and when express these negative feelings.

The researchers used discussion, role play, social events, one to one interaction, and demonstrations with participants to practice new skills.

\section{b- Preparing patients:}

Preparing patients to be involved in the study was established by the researchers through introductory phase. Rapport with patients, introduce each one to other patients and researchers facilitate feeling of warmth and security

\section{c- Assessment and data collection :(pre test )}

All participants completed all pre-study tools before the beginning of the program. This assessment was completed through patients 'interview, revision of patients' records and rechecked by the psychiatrist for patients' assessment for signs and symptoms.

\section{2- Introductory phase:( 2 sessions):}

An acquaintance between researchers and participants was made, brief explanation was done on signs and symptoms of chronic schizophrenia, immediate influence of these signs and symptoms on patients interaction with others, and how gradually patient become withdrawn.

\section{3- Implementation phase: ( 12 sessions):}

In this stage, researchers started by easy and widely accepted more difficult contents. The meetings were twice weekly at the same time and in the same room (at the ward).

Discussion about planned activities and demonstration of new skills were done. New skills as effective expression of negative feelings as anger or tension were learnt through guidance, demonstration, and practice, while role play was used to aid the better performance as practice of different patients' behaviors as assertive, aggressive and passive as to aid in better performance

After participants had practiced and applied new skill, the researchers distributed the assignment to facilitate transferring the newly acquired skills into practice stage. Participants were reinforced to participate in planned activities as role play, demonstration and practice of the skills by explaining the benefits of practicing as to initiate and maintain relationship with others, relieving tension by expressing negative feeling effectively and stand up of their rights rather than being passive

Researchers used open -ended questions, warmth and concern with participants' problems as the patients refused to interact with group and practice taught skill. Group interaction was observed and recorded in each session as patient who accepts to interact with only one patient and refused to interact with all other patients. The final 10 minutes at each session was for summary, and this summary focused on skill that learnt during the session

Evaluation for each session was done through, immediate feedback from participants and patients' assignments, the researchers prepared the final two sessions for termination, date for another assessment (follow up) after three months was determined. 
The content of the training program sessions was as follows: 1. Introduction about the concept of assertiveness; the importance of the assertiveness for patients. 2. Comparison of passive, aggressive, and assertive behavior. 3. The individual's basic rights of assertive behavior. 4. How to say "No" assertively. 5. How to make a request assertively. 6 . How to respond and give criticism assertively; and give constructive criticism. 7. Handle and express anger assertively. 8. How to give and accept compliments assertively; and how to make apology assertively. 9. How to promote self esteem. It was difficult to control the time for each session because the patients were interested in the subject of each session. To ensure that the patients reached the objective of each session, each session started by a feedback about the previous one.

\section{4- Evaluation phase ( last session):}

Participants were reassessed by using the same tools of pre test and comparison was done to determine the effectiveness of the program evaluation

\section{Procedure:}

After obtaining the official approval from the ethical committee of sciencitific research at the faculty of nursing, Cairo University as well as official approval from ethical committee of sciencitific research at ALAbassia psychiatric mental health hospital.Also, obtaining official approval from director of in-patient female departments at AL-Abassia psychiatric mental health hospital. The researchers interviewed all participants before they enter the program. The study purpose was explained and oral consent was obtained, then written consent was obtained immediately before filling the tools. The researchers used semi structured interview to complete tools for patient assessment, this interviewed lasted for about 30-45 minutes, also researchers' observations for patients communications and interactions with other patients, also severity of symptoms. These tools were kept anonymously by using code number. The purpose of the study was explained for psychiatrists and nursing staff of all selected wards for chronic patients to gain support and corporations. Fixed time and room were determined for program sessions.

\section{Pilot study}

A Pilot study was carried out on 6 institutionalized female patients with chronic schizophrenia, who were excluded from the actual study, to ensure the clarity and the applicability of the study measures. No modifications were needed to test the feasibility and the applicability of the study tools. Subjects who will participate in the pilot study will be excluded from the actual study.

\section{Ethical Considerations:}

Primary permission was attained from the ethical committee of scientific research at the Faculty of Nursing - Cairo University. Also official permission was also obtained from AL-Abassia mental health hospital. Study procedure was reviewed and approved by the Human Rights Protection Committee of the General Secretariat of Mental Health in Egypt. An official approval was also obtained from the director of El- Abassia mental health hospital and from the director of female wards to conduct the study. Study participants were informed that they have the right to refrain from participating in the study at any time without experiencing any negative consequences. Informed consents were obtained from all eligible participants who agreed to participate in the study. Data confidentiality and patients' privacy were secured. Code numbers were created and kept by the researchers to keep patients' anonymity.

\section{Statistical Design}

Data were analyzed by using the Statistical Package for the Social Sciences statistical software (SPSS version 20). Descriptive statistics were computed to examine data distributions and to summarize data. Correlation Wilcoxon and Friedman, F- test were used to test the statistical significant differences between the pre and post assessment. According to the baseline scores of the social interaction anxiety and Rosenberg selfesteem scales, comparison was done between pre/ post and follow up assessment for study group using paired- $t$ test. Mean change was used to calculate the change after program sessions, Reported $p$ values with level of significance set at $\mathrm{p}<.05$.

\section{Results}

This study was conducted on fifteen institutionalized patients with chronic schizophrenia to investigate the impact of assertive training program on their social anxiety and self esteem. Data collection method was utilized and the results of this study were presented in the following four main sequences:

Table (1): demonstrated that the age of the studied sample ranged between 30-60 years, about three fourth of the sample (73.2\%) their ages were40-49 and their duration of illness was 10-15 years. More than half of them were institutionalized for more than ten years 
Table (1): Demographic Characteristics of studied Group ( $\mathrm{n}=15)$ :

\begin{tabular}{|l|l|l|}
\hline Demographic Characteristics & \multicolumn{2}{|c|}{ studied group $\mathrm{n}=15$} \\
& No. & \\
\hline Age: & & 13.4 \\
\hline $30-$ & 2 & 73.2 \\
\hline $40-$ & 11 & 13.4 \\
\hline $50-60$ & 2 & 100 \\
\hline Total & 15 & \\
\hline Duration of illness: & & 6.8 \\
\hline $1-$ & 1 & 0 \\
$5-$ & 0 & 73.2 \\
$10-$ & 11 & 20 \\
$15-$ & 3 & 100 \\
\hline Total & 15 & \\
\hline Duration of institutionalization : & & 13.3 \\
1years - & 2 & 33.3 \\
5 years- & 5 & 53.4 \\
10 years- & 8 & $100 \%$ \\
\hline Total & 15 & \\
\hline
\end{tabular}

Table (2): showed that pre and post patients mean scores regarding dependent studied variables (social interaction anxiety and self-esteem). The social anxiety mean scores for post group was significantly different from the mean score for pretest $(50.13 \pm 10.80,34.33 \pm 8.32)$ respectively at $\mathrm{P}=0.002$. As regarding to self esteem scale for the post test there was no statistically significant difference between the mean scores of the pretest $(20.33 \pm 4.38)$ and for the post intervention $(21.86 \pm 1.72$ at $\mathrm{P}=0.182)$.

Table (2): Comparison between mean scores of Pre and Post assessment Regarding Dependent Studied Variables $(n=15)$.

\begin{tabular}{|l|l|l|l|l|}
\hline Variables & $\begin{array}{l}\text { Pre(T1) } \\
\text { Mean } \pm \text { SD }\end{array}$ & $\begin{array}{l}\text { Post(T2) } \\
\text { Mean } \pm \text { SD }\end{array}$ & Wilcoxon & P \\
\hline Social Anxiety: & & & & \\
-Interaction anxiety & $17.73+4.19$ & $12.93 \pm 4.11$ & -2.57 & $0.01^{* *}$ \\
- Avoidance anxiety & $18.26+5.13$ & $11.26 \pm 3.78$ & -2.93 & $0.003^{* * *}$ \\
-initiation anxiety & $14.13+3.77$ & $10.13 \pm 2.85$ & -2.17 & $0.03^{* *}$ \\
\hline Total & $50.13+10.80$ & $34.33+8.329$ & -3.06 & $0.002^{* * *}$ \\
\hline Self- esteem & $20.33+4.38$ & $21.86+1.726$ & -1.33 & 0.182 \\
\hline Total & $70.46+9.60$ & $55.20+7.36$ & -3.14 & $0.002^{* * *}$ \\
\hline
\end{tabular}

Statistically significant at $\mathrm{P}<0.001 * * *$

Table (3): represented percentage of improvement regarding dependent variables (social anxiety and self esteem) in post intervention. This table showed the mild increasing self esteem that was $4.09 \%$. Concerning dimensions of social anxiety, interaction anxiety was $10.6 \%$, avoidance anxiety was $14.39 \%$ and initiation anxiety was $13.76 \%$. Improvement occurred for post intervention test for patients who received assertiveness training program.

Table (3): Range of post assessment Improvement Regarding Dependent Variables (social interaction Anxiety, and self-esteem) among the studied Group ( $\mathrm{n}=15)$.

\begin{tabular}{|l|l|}
\hline Variables & Percentage\% \\
\hline - self esteem: & 4.096 \\
\hline Social Anxiety: & \\
-Interaction anxiety & 10.60 \\
- Avoidance anxiety & 14.39 \\
-initiation anxiety & 13.76 \\
\hline
\end{tabular}

Table (4): revealed that, there were no statistically significant correlations between patients' age groups and social anxiety scale(interaction, avoidance and initiation anxiety) and self-esteem scale.

Table (4): Correlational analysis between patients 'age and duration of illness, dimensions of social anxiety and their self esteem $(\mathrm{n}=15)$.

\begin{tabular}{|l|l|l|l|l|l|}
\hline Variables & Patients 'Age group & \multirow{2}{*}{ Friedman } & \multirow{2}{*}{ P } \\
\cline { 2 - 5 } & $\begin{array}{l}30- \\
\mathrm{N}=2\end{array}$ & $\begin{array}{l}40- \\
\mathrm{N}=11\end{array}$ & $\begin{array}{l}50+ \\
\mathrm{N}=2\end{array}$ & \\
\hline - self esteem: & $22.83+5.81$ & $25.36+2.10$ & $25.33+1.50$ & 2.165 & .127 \\
\hline Social Anxiety scale: & $13.33+7.03$ & $14.78+4.33$ & $14.33+4.27$ & .246 & .783 \\
\hline -Interaction anxiety & $15.00+6.78$ & $13.36+4.80$ & $13.50+7.47$ & .230 & .795 \\
\hline
\end{tabular}


Effect Of Assertive Training Program On Social Interaction Anxiety And Self - Esteem Of...

\begin{tabular}{|l|l|l|l|l|l|}
\hline - Avoidance anxiety & & & & & \\
\hline -initiation anxiety & $10.66+5.24$ & $11.66+3.03$ & $11.16+5.45$ & .206 & .815 \\
\hline Total social anxiety scale: & $39.00 \pm 18.35$ & $39.81 \pm 9.98$ & $39.00 \pm 15.42$ & .020 & .980 \\
\hline
\end{tabular}

Table (5): revealed that,. There were significant negative correlations among patients' initiation interaction anxiety domain and their self -esteem with their duration of institutionalization at $\mathrm{P}=008$ and 0.02 respectively.

Table (5): Correlational analysis between patients 'duration of institutionalization and dimensions of social interaction Anxiety and self-esteem $(\mathrm{n}=15)$

\begin{tabular}{|c|c|c|c|c|c|}
\hline \multirow[t]{2}{*}{ variables } & \multicolumn{3}{|c|}{ Duration of institutionalization } & \multirow[t]{2}{*}{$\mathrm{F}$} & \multirow[t]{2}{*}{$\mathrm{P}$} \\
\hline & 1years- & 5years- & 10years - & & \\
\hline Self esteem & $20.33+8.082$ & $25.48+2.017$ & $24.88+1.615$ & 5.453 & $.008 * *$ \\
\hline \multicolumn{6}{|l|}{ Social anxiety scale : } \\
\hline Interaction anxiety & $14.50+5.28$ & $13.90+4.16$ & $16.66+4.89$ & 1.276 & .290 \\
\hline avoidance anxiety & $17.33+5.77$ & $13.03+5.08$ & $14.44+6.18$ & 1.030 & .366 \\
\hline initiation anxiety & $10.33+7.50$ & $15.60+3.161$ & $17.33+4.33$ & .168 & $0.02^{*}$ \\
\hline Total: & $42.66 \pm 21.93$ & $38.54 \pm 10.55$ & $42.44 \pm 13.24$ & .487 & .618 \\
\hline
\end{tabular}

Table (6): showed that, highly significant differences were found among pre, post and follow -up assessment at $\mathrm{P}=0.001$.

Table (6): Comparison among pre, post and follow-up mean scores assessment of dependent variables

\begin{tabular}{|l|l|l|l|l|}
\hline Pre( T1) & Post(T2) & Follow-up(T3) & Chi-square & p \\
\hline $75.46+9.60$ & $59.20+7.36$ & $61.20+7.36$ & 20.57 & $.001 * *$ \\
\hline
\end{tabular}

Table (7): showed the correlation matrix of social anxiety scale and self esteem scale. The table demonstrated negative significant correlation between social anxiety scale and self esteem scale $(p=0.027)$. Generally, self esteem has been affected by social anxiety.

Table (7): Correlation Matrix between participants social interaction Anxiety and their self esteem $(n=15)$

\begin{tabular}{|l|l|l|}
\hline Variables & Social Anxiety & Self esteem \\
\hline Social Anxiety & 1 & \\
\hline Self esteem & $0.027^{* *}$ & 1 \\
\hline
\end{tabular}

\section{Discussion}

This study aimed to investigate the effects of assertiveness training program on social interaction anxiety and self-esteem among female institutionalized patients with chronic schizophrenia. Those patients often experienced lack or deteriorations in their social skills with institutionalization which reflected negatively over their self-esteem.

\section{Demographic characteristics of the Institutionalized Chronic Schizophrenic Patients:}

The distribution of the sample according to their ages, duration of illness and duration of institutionalization of the present study (Table, 1) showed that, about three fourth of the sample, their age ranged from 40 years to 50 years, and their duration of illness was more than 10 years, while more than half of the participants had institutionalized for more than 10 years. This feature could be due to chronicity of mental illness which imposes lots of limitation on patients' performance and functioning in accordance with stigma toward mental illness, these factors lead to poor prognosis, patients' rejections from the community and institutionalization. This finding was in accordance with Kumar, \& Singh (2015) who they found that, schizophrenic patients who were institutionalized for more than five years were mainly lack of integration with community programs that promote their mental, psychological and social wellbeing.

\section{Effectiveness of assertive training program:}

Regarding effectiveness of assertive training program among institutionalized patients with chronic schizophrenia, there were statistically significant changes post intervention than before regarding participants' social interaction anxiety and self-esteem where pre intervention( Mean $=70.46$ ) while post intervention (Mean $=55.20)$ at $($ p0.002)(table: 2). This result could be interpreted as nursing intervention program was effective on reducing participants social anxiety and improve their self esteem

A probable reason for lowering interaction anxiety skills and slight change of self-esteem may be due to the fact that participation in the program has helped the institutionalized patients who were less assertive or even passive or aggressive schizophrenic patients to practice some assertive skills in a therapeutic environment through involvement in a real social situation with others in a right manner and appreciation of their practices

\begin{tabular}{lll|l}
\hline DOI: $10.9790 / 1959-0505033644$ & www.iosrjournals.org & 42 Page
\end{tabular}


which in accordance affects their self-esteem. While highly significant increase of the mean score of self-esteem were at 0.001 post program than preprogram. This could be attributed to that social behavior of schizophrenic patients is non-assertive and the primary goals of the program are to maintain some degree of connectedness with others, avoid other rejection and help patients to be more constructive and confident in dealing with situations in building the relationships they want. These results were congruent with Barakat, Khodiar, Elmalky, \&Elashry, (2015) who examined the effect of assertive training program on participants' assertiveness and selfesteem; they found that, assertiveness training program had positive effect on development of assertiveness skills and promotion of self-esteem of the schizophrenic patients after receiving the training program.

Also in the same line, \&Seo, AhnAffiliations, Byun, \& Kim, (2007), Lin, et, al., (2008) and Lee, et al., (2013) who showed that, there was significant improvement with respect to the experimental group on the assertiveness levels of the psychotic patients, that would benefit more from the assertiveness training program for the change in how they viewed themselves, improved their assertiveness, properly expressed their individual moods and thoughts and further establishment of self-esteem.

On the same dimension Hou, et al., (2004) revealed that, assertiveness training can improve patient's social skills and emotional health which is a process of learning to stand up for one's rights and cope assertively, not passively or aggressively. While, on the other side, these findings were incongruent with Cheung, (2006) who pointed out that, almost all experimental studies of group treatments with psychiatric patients have shown no significant results for assertive behavior on participants' social interaction anxiety and interpersonal relationships

Comparing between the mean changes of self-esteem scores of the studied sample post program implementation (table 2), and the present study, showed that, there was a little change of the mean score of selfesteem post program implementation. This means that assertive training program was effective to help patients to express of positive or/and negative feelings easily which could help in being more confident and lead to some change of self-esteem score. This result was consistent with (Shimizu et., al. 2004, Hashemi, 2007, Pan \& Dai, 2008, \& Kashani \& Bayat, 2010) who stated that, assertiveness training was a life skill that causes an increase in self-esteem through rationale stating of thoughts and feelings, improvement in social and relational skills, and respecting other's rights. On the other hand, this finding is not consistent with the previous study by (Killaspy, et al. 2006), who found that the outcomes of their study have not shown any changes in patient's self-esteem in acute psychiatric settings.

The high percentage regarding improvement of social interaction anxiety post intervention was mainly related to avoidance anxiety among participants (table: 3), this may occur in response to nature of the program sessions that depend on participants 'active role rather than passivity; and participants were instructed to behave assertively in role-playing situations .During the role playing and actual real situations, participants were encouraged to praise each other using positive expression, which encouraged communication skills and improve interaction.

The present study result revealed that, there was statistically significant negative correlation between self-esteem and social anxiety of the studied samples pre and post program implementation (table: 7). This means that with reduction of participants social anxiety, their self-esteem will improve. This result was consistent with (Ratson, 2011\& Tavakoliet al., 2014), who reported that, assertiveness techniques have indirect strong relationship with social interaction anxiety, which helped each participant for assertive self-expression and defend her rights to say her opinion. While, on the other hand, the low level of self-esteem will result in many psychological, physical, and social problems which lead to more social isolation and withdrawal.

In the same track, (Shimizuet al., 2004) pointed out that, there was two ways relationship between assertiveness and self-esteem. It seems that assertiveness causes an increase in self-confidence, interpersonal relations, and internal control. This result corresponded to the previous results by (Ibrahim, 2010 and Kirst, 2011), who found a high level of assertiveness correlated positively and significantly with a high level of selfesteem, as when the person being assertive can help to boost their level of self-esteem. Also, Marcon, (2010) emphasized on the role of patients' behavior (either assertive or non-assertive) as considered to be vital prerequisite for self-esteem.

The current study showed that there were significant relations between initiation anxiety domain, selfesteem and duration of hospitalization (at $\mathrm{P}=0.02$ ) (table: 5), this finding may be related to institutionalization itself that cause major deterioration in a majority of skills that negatively affects patients communication and interaction. This is consistent with (Ku et al., ( 2007) Who found that, with chronicity of illness in addition to institutionalization, patients start to escape from reality, use more less effective coping methods and become more socially isolated due to anxiety about interactions or over hostile behavior .

The present study results revealed that, there was no statistically significant relation-ship among patients' age groups and social anxiety scale and self esteem scale. This result corresponded to Shamsunnisah, \& Hasanah, (2008), who found that, there were no association found between age, the level of self-esteem and 
social anxiety of schizophrenia patients. While on the other side this result disagreed with (Hemmati, et al., 2014) who stated that, self-esteem is an important factor which had influence on age of an individual.

The results of the study contributed to the facts that assertive behavior can be learnt and self-esteem can be enhanced through assertiveness training (Abdel-Aleem, 2007). The results of this study were consistent with the study hypothesis that the assertive training program will improve social anxiety, and enhance selfesteem of schizophrenic patients.

\section{Conclusion}

The findings of the present study indicated that the assertiveness program had a positive effect on social interaction anxiety and self-esteem of the schizophrenic patients after receiving assertiveness training program. There was a highly statistically significant negative correlation between the total social anxiety and self-esteem level of the studied sample. While there was a highly statistically significant positive correlation between total social interaction anxiety and self esteem of the studied sample pre/ post program implementation.

\section{Recommendation}

This study recommended continuous follow-up for schizophrenic patients participating in assertiveness training program to support and boost their learning skills.

Further studies, using a larger probability sample and male patients for generalization of the results. The application of this program in day care, outpatients' clinics and community service program to improve their social interaction

\section{Limitation:}

This study involved only institutionalized schizophrenic patients of Al abbasia mental health hospital, hence result might be limited to the setting.

\section{References}

[1]. Allas, A. (2014). Effectiveness of Assertiveness Training on Self Esteem among Adolescent Girls.M.Sc. Nursing Dissertation protocol submitted toRajiv Gandhi University of Health Sciences, Karnataka, Bangalore.

[2]. Abo ElElla,E,. Hashim,N; Elhabiby,M;Khalil,S; Shorab,I\&Mounir, M. (2015). Negative symptoms and functioning in institutionalized versus outpatient schizophrenic patients.Middle East Current Psychiatry. 22:65-69.

[3]. Barakat, M., Khodiar,A., Elmalky, M., \&Elashry, N. (2015). The Effect of an Assertiveness Training Program on Schizophrenic Patients.Benha University.

[4]. Ebrahimi, H., Navidian, A., \&Keykha, R. (2014). Effect of Supportive Nursing Care on Self Esteem of Patients Receiving Electroconvulsive Therapy: A Randomized Controlled Clinical Trial. J Caring Sci.; 3(2): 149-156.

[5]. ElGamal, M., Eltybani,M., \&Bassim, R. (2012). Psychiatric Morbidity of Chronic Institutionalized Patients With Schizophrenia (Implications For Future Community Care).The Egyptian Journal of Psychiatry. http://www.new.ejpsy.eg.net/images/logo.png

[6]. Çeçen-Erogul, A. R., \&Zengel, M. (2009). The Effectiveness of an Assertiveness Training Program on Adolescents' Assertiveness Level. Elementary Educational Online, 8 (2), 485-492.

[7]. Degleris,N., Mantelou,E., Solias,A., Karamberi,D.,\&Mulinte,A.(2008)Assertiveness training as a major component element of a psychoeducational program addressed to psychiatric patients and their families.Annals of General Psychiatry, 7(Suppl 1):S300 doi:10.1186/1744-859X-7-S1-S300

[8]. Ho, R.,Wan, A.,Au-Yeung, F., Yan Lo, P., Siu, P., Wong, C.,Han Ng, W.,Cheung, I., Man Ng, S., Chan, C., \& Chen, E. (2014).The psychophysiological effects of Tai-chi and exercise in residential Schizophrenic patients: a 3-arm randomized controlled trial. BMC Complementary and Alternative Medicine, 14:364.

[9]. Kumar, B., \& Singh, A. (2015). Efficacy of Social Skills Training for the Persons with Chronic Schizophrenia.The Qualitative Report 2015 Volume 20, Number 5, Article 7, 660-696 http://www.nova.edu/ssss/QR/QR20/5/kumar7.

[10]. Lee, Y., Chang, C., Chu H., Yang C. -Y., Ouk, L., Chung, H. \& Chou, R. (2013). The Effects Of Assertiveness Training In Patients With Schizophrenia: A Randomized, Single-Blind, Controlled Study. Journal of Advanced Nursing 69(11), 2549-2559. doi: 10.1111/jan.12142.

[11]. Lin, Y., We, M., Yang, C., Chen, T., Hse, C., Chang, Y. Tzengw., Chou, Y. \& Chou, K. (2008): Evaluation of assertiveness training for psychiatric patients. Journal of clinical nursing, 17: 2875-2885. http://dx.doi.org/10.1111/j.1365-2702.2008.02343.x.

[12]. Langdon, R., Connors, M., \&Connaughton, E. (2014). Social Cognition and Social Judgment in Schizophrenia.Volume 1, Issue 4, Pages 171-174. Open Access: http://dx.doi.org/10.1016/j.scog.2014.10.001

[13]. Mahmoud, S., \&Abd Hamid, R. (2013). Effectiveness of Assertiveness Training Program on Self Esteem \& Academic Achievement in Adolescents Girls at secondary school at Abha city. J Am Sci; 9(8):262-269. http://www.jofamericanscience.org.

[14]. Rosenberg, M. (1965).Society and the Adolescent Self-Image. Princeton, NJ: Princeton University Press.

[15]. Seo, J. M., AhnAffiliations, S., Byun, K., \& Kim, C. (2007): Social Skill Training As A Nursing Intervention to Improve The Social Skill and Self-Esteem of In Patients With Chronic Schizophrenia. Arch PsychiatrNurs; 21(6): 317- 26. http://dx.doi.org/10.1016/j.apnu.2006.09.005.

[16]. Videbeck, S., \& Miller, C. (2011).Psychiatric - Mental Health Nursing. $5^{\text {th }}$ ed., Philadelphia: Walters Kluwer health $\backslash$ Lippincott Williams \&Wilkins.

[17]. Yadav, B. (2015). Efficacy of Social Skills Training in Schizophrenia: A Nursing Review. Current Nursing Journal; Volume 2, Number 1. http://www.intermedcentral.hk/ 